\title{
Effects of Chronic Olanzapine and Haloperidol Differ on the Mouse NI Auditory Evoked Potential
}

\author{
Christina R Maxwell', Yuling Liang', Bryanne D Weightman', Stephen J Kanes², Ted Abel', Raquel E Gur², \\ Bruce I Turetsky ${ }^{2}$, Warren B Bilker ${ }^{4}$, Robert H Lenox ${ }^{5}$ and Steven J Siegel*, I,2 \\ 'Division of Neuropsychiatry, Department of Psychiatry, Stanley Center for Experimental Therapeutics in Psychiatry, University of Pennsylvania, \\ Philadelphia, PA, USA; ' 2 Division of Neuropsychiatry, Department of Psychiatry, University of Pennsylvania, Philadelphia, PA, USA; ${ }^{3}$ Department of \\ Biology, University of Pennsylvania, Philadelphia, PA, USA; ${ }^{4}$ Department of Biostatistics and Epidemiology, University of Pennsylvania, Philadelphia, \\ PA, USA; ${ }^{5}$ Department of Psychiatry, University of Pennsylvania, Philadelphia, PA 19104, USA
}

\begin{abstract}
Auditory evoked potentials have been used in a variety of animal models to assess information-processing impairments in schizophrenia. Previous mouse models have primarily employed a paired click paradigm to assess the transient measures of auditory gating. The current study uses stimulus trains at varied interstimulus intervals (ISI) between 0.25 and $8 \mathrm{~s}$ in mice to assess the effects of chronic olanzapine and haloperidol on auditory processing. Data indicate that olanzapine increases the amplitude of the N40, P80, and P20/N40 components of the auditory evoked potential, whereas haloperidol had no such effect. The ISI paradigm also allowed for an evaluation of several components of the mouse evoked potential to assess those that display response properties similar to the human P50 and NI 00 . Data suggest that the mouse N40 displays an ISI response relationship that shares characteristics with the human NI00, whereas the P20 appears more consistent with the human P50 across the ISI range evaluated in this task. This study suggests that olanzapine may help improve N100 impairments seen in schizophrenia, while haloperidol does not.

Neuropsychopharmacology (2004) 29, 739-746, advance online publication, 2 I January 2004; doi: I 0. I 038/sj.npp. 1300376
\end{abstract}

Keywords: event-related potential; mouse; haloperidol; olanzapine; NI/NI00; schizophrenia

\section{INTRODUCTION}

Schizophrenia is a debilitating neuropsychiatric disease with positive symptoms including hallucinations, delusions and paranoia, and negative symptoms including social dysfunction and memory impairments. Antipsychotic drugs commonly used to treat positive symptoms include haloperidol, which has high affinity at the D2 receptor and is considered to be a selective D2 antagonist at clinical doses, and olanzapine, which also displays a high affinity for the D2 receptor as well as binding to $5 \mathrm{HT} 2 \mathrm{~A}$ receptors at clinical doses (Beasley et al, 1996). Previous reports indicate that selective agents, such as haloperidol, and multireceptor agents, such as olanzapine, may be distinguished by their ability to reverse nonsymptom-based endophenotypes of schizophrenia (Cadenhead and Braff, 2002; Light et al,

\footnotetext{
*Correspondence: Dr SJ Siegel, Division of Neuropsychiatry, Stanley Center for Experimental Therapeutics in Psychiatry, Clinical Research Building Rm. 145a, 4I5 Curie Boulevard, University of Pennsylvania, Philadelphia, PA 19104, USA, Tel: + I 215573 0278, Fax: + I 215 662 7903, E-mail: siegels@mail.med.upenn.edu

Received 13 May 2003; revised 17 November 2003; accepted 20 November 2003

Online publication: 2 December 2003 at http://www.acnp.org/citations/ Npp | 2020303210/default.pdf
}

2000). These have been proposed to reflect the basic neurobiological markers for disease vulnerability including impairments of attention, cognitive function, and sensory gating, as measured by auditory and visual evoked potentials. (Cadenhead and Braff, 2002; Myles-Worsley, 2002).

Impairments of auditory evoked potentials have been extensively studied as an endophenotypic marker of schizophrenia. The human auditory evoked potential can be divided into three subsets of latency-defined components that correspond to progression of brain activity related to the auditory stimulus through the auditory pathway. Early components (wave I-VI) originate in the cochlea and auditory nuclei of the brainstem, while mid-latency components (including the P50) occurring between 8 and $50 \mathrm{~ms}$ are thought to correspond to the activation of auditory thalamus and auditory cortex (Picton et al, 1974). The longer latency components (including the N100 and P200) have been localized to the primary auditory cortex and cortical association areas (Gallinat et al, 2002).

Mid-latency and longer latency components of auditory evoked potentials evaluated in many human studies are named for either position or latency. The first major positive deflection commonly studied is known as the P1 or P50, and occurs at approximately $50 \mathrm{~ms}$ post-stimulus. The 
first major negative deflection is the $\mathrm{N} 1$ or N100, with a latency of approximately $100 \mathrm{~ms}$. The second positive deflection is called the P2 or P200, and has a latency of approximately $200 \mathrm{~ms}$. Relative topology of the P1, N1, and $\mathrm{P} 2$ is consistent across species, although the analogous components between humans and animals are debated.

The current study utilizes a mouse model to assess the ability of two antipsychotic medications to rectify sensory processing abnormalities that have been demonstrated in schizophrenia. Specifically, some patients with schizophrenia show an impaired gating of auditory evoked potentials (Boutros et al, 1999; Erwin et al, 1994; Stevens et al, 1997). Sensory gating refers to the ability of the brain to modulate its sensitivity to the incoming sensory stimuli (Braff and Geyer, 1990). Two tasks that measure the sensory gating of event-related potentials (ERPs) are the paired click paradigm, as a transient gating measure, and the interstimulus interval paradigm (ISI), as a steady-state gating measure (Erwin et al, 1994). The paired click paradigm contains two tones presented $500 \mathrm{~ms}$ apart with a 9-s interval between pairs, while the ISI task typically utilizes trains of stimuli at short intervals ranging from 0.25 to $1 \mathrm{~s}$ and longer intervals ranging from 2 to $10 \mathrm{~s}$. During the ISI task in human studies, the amplitude of the N100 decreases with decreasing interstimulus intervals in healthy individuals (Boutros et al, 1999; Javitt et al, 2000). In contrast to the N100, the amplitude of the human P50 does not increase with increasing interstimulus intervals ranging from 1 to $16 \mathrm{~s}$ (Javitt et al, 2000; McFarland et al, 1975; Onitsuka et al, 2000). While some reports suggest that the human P200 displays an increase in amplitude with increasing ISI, to our knowledge, the human P200 has not been thoroughly investigated using this paradigm (Budd et al, 1998; Shelley et al, 1999). Studies using the ISI method have shown that schizophrenia patients have a decrease in amplitude of the N100 response to the ISI paradigm compared to controls (Shelley et al, 1999).

The neurobiology of sensory processing deficits in schizophrenia has been investigated with auditory ERPs in monkeys, cats, rats, and mice, using tasks similar to those used in humans (Boutros et al, 1997; de Bruin et al, 1999; Javitt et al, 2000; Pincze et al, 2001; Siegel et al, 2003; Simosky et al, 2003; Stevens et al, 2001, 1997). To interpret the findings in these studies, it is important to understand the relationship between auditory evoked components in the species being studied and the analogous components in human. Earlier studies in monkey utilized the refractory response relationship at different ISI to link specific components in monkey and human. These studies indicate that the monkey P1 occurring between 5 and $40 \mathrm{~ms}$, displays an increasing amplitude at ISI between 150 and $450 \mathrm{~ms}$ and plateaus, in response to intervals exceeding $1 \mathrm{~s}$ similar to the human P50 (Javitt et al, 2000). However, the monkey N1, occurring between 40 and $120 \mathrm{~ms}$, increases in amplitude following interstimulus intervals ranging from 150 to $4.5 \mathrm{~s}$, similar to the human N100 (Javitt et al, 2000; Onitsuka et al, 2000).

Auditory evoked components commonly examined in rodents include the $\mathrm{P} 1$ (positive deflection at $20-30 \mathrm{~ms}$ ), the $\mathrm{N} 1$ (negative deflection at $40-50 \mathrm{~ms}$ ), and the P2 (positive deflection at $80-100 \mathrm{~ms}$ ). These components are also named for latency, P30, N50, and P80 in rats and P20, N40, and P80 in mice (Iwanami et al, 1994; Siegel et al, 2003). The analogous components between the rodent and human are debated (Adler et al, 1986; Ehlers et al, 1997; Miyazato et al, 1999a, b). In mice, Simosky and Stevens consider the mouse $\mathrm{N} 40$ to be analogous to the human P50, but we believe that the mouse N40 is analogous to the human N100 (Siegel et al, 2003; Simosky et al, 2003).

One aim of this study is to use the interstimulus interval paradigm to evaluate the human analogue of the mouse N40. Since the human N100 has a well-defined ISI response with intervals ranging from $75 \mathrm{~ms}$ to $9 \mathrm{~s}$ and the human P50 amplitude plateaus at intervals greater than $1 \mathrm{~s}$, we hypothesized that the mouse $\mathrm{N} 40$ would display an ISI relationship between $250 \mathrm{~ms}$ and $8 \mathrm{~s}$, while the mouse P20 would not. While limited research suggests that the P200 displays an increase in amplitude with increasing ISI, we are uncertain as to whether the P80 will show such an effect using the ISI task in this study (Budd et al, 1998; Shelley et al, 1999).

This study also examines the effects of chronic olanzapine and chronic haloperidol on the P20, N40, and P80 components of the mouse ERP across ISI as a model of the pharmacological effects on the human P50, N100, and $\mathrm{P} 200$. Additionally, the P20/N40 difference waveform was calculated to facilitate a comparison with previous literature (Cook et al, 1968; Stevens et al, 1996). This animal model is intended to elucidate the neurobiology of sensory processing as well as helping to clarify differences among the effects of different antipsychotic medications on sensory processing phenotypes.

\section{METHODS}

\section{Animals}

C57BL/6J mice were obtained at 8 weeks of age from Jackson Laboratories (Bar Harbor, ME). A total of 26 control mice were examined in the component analysis portion of this study, and 55 mice were tested in the antipsychotic treatment experiments. Eight control mice overlapped between the two portions of this study but had identical conditions, including identical implantation of electrodes and pumps, identical vehicle in the pumps, as well as identical stimulus and testing conditions including the time of day. The only difference between the eight mice included in the drug portion of the study and the remaining 18 mice was the day on which they were tested. Additionally, there was no statistical difference between these groups of control mice on any component of the auditory evoked potential $\{\mathrm{P} 20(\mathrm{~F}(1,24)=1.7, p=0.21) ; \mathrm{N} 40$ $(\mathrm{F}(1,24)=0.09, p=0.76) ; \mathrm{P} 80(\mathrm{~F}(1,24)=0.04, p=0.83)\}$. Therefore, all 26 mice were used in the stimulus response portion of the study. All testing was conducted between 9 and 11 weeks of age. All protocols were conducted in accordance with University Laboratory Animal Resources guidelines, and were approved by the Institutional Animal Care and Use Committee. Mice were housed 4-5/cage in a light- and temperature-controlled Association for Assessment and Accreditation of Laboratory Animal Careaccredited animal facility. Water and standard rodent chow were available ad lib. Experiments were conducted in the Stanley Center for Experimental Therapeutics in Psychiatry 
at the University of Pennsylvania. All behavioral testing was performed during the light phase between the hours of 0900 and 1300 . Mice were acclimated to the housing facility for 1-2 weeks prior to behavioral testing.

\section{Treatment Groups}

Olanzapine 1, 2.5, and $5 \mathrm{mg} / \mathrm{kg} / \mathrm{day}$ (Eli Lilly and Co, Indianapolis, IN), haloperidol $0.5,1$, and $2 \mathrm{mg} / \mathrm{kg} / \mathrm{day}$ (Sigma Aldrich, St Louis, MO), and vehicle PEG400 (Sigma Aldrich, St Louis, MO) were delivered through subcutaneous Alzet micro-osmotic pumps (Durect Corp. Model 1002, Cupertino, CA) 7 days prior to electrode surgery and 14 days prior to testing. Previous studies have displayed the stability of haloperidol and olanzapine in micro-osmotic pumps over at least 14 days (Andersen and Pouzet, 2001; Frey, 1983; Gysling and Beinfeld, 1984; Kaplan et al, 1999; McMillen, 1985; Tarazi et al, 2002). There were eight mice in each treatment group except for olanzapine 2.5 which had seven mice.

\section{Surgery}

Animals underwent stereotaxic implantation of tripolar electrode assemblies (PlasticsOne Inc., Roanoke, VA) for nonanesthetized recording of hippocampal auditory evoked potentials 7 days later. Animals were anesthetized with ketamine hydrochloride/xylazine $(100 / 10 \mathrm{mg} / \mathrm{kg})$ prior to surgery. The surgical coordinates were measured relative to bregma in the $x, y$, and $z$ dimensions. Three stainless steel electrodes, mounted in a single pedestal, were aligned along the sagittal axis of the skull at $1 \mathrm{~mm}$ intervals, with precut lengths of $3.0 \mathrm{~mm}$ (positive) and $1.0 \mathrm{~mm}$ (ground and negative). Positive electrodes were placed in the CA3 hippocampal region $1.4 \mathrm{~mm}$ posterior, $2.65 \mathrm{~mm}$ lateral, and $2.75 \mathrm{~mm}$ deep relative to bregma. Negative electrodes were placed adjacent to the ipsilateral cortex at $0.6 \mathrm{~mm}$ anterior, $2.65 \mathrm{~mm}$ lateral, and $0.75 \mathrm{~mm}$ deep relative to bregma. Ground electrodes were located between recording and reference at $0.4 \mathrm{~mm}$ posterior, $2.65 \mathrm{~mm}$ lateral, and $0.75 \mathrm{~mm}$ deep to bregma. The electrode pedestal was secured to skull with cyanoacrylic gel (PlasticsOne, Roanoke, VA). Following surgery, animals were individually housed. Electrode tips were marked with the Perls iron reaction and location was verified within the target zone (LaBossiere and Glickstein, 1976).

\section{Recording}

Recording of evoked potentials was performed 7 days after implantation of electrodes, which was 14 days after implantation of the micro-osmotic pumps. Stimuli were generated by Micro1401 hardware and Spike 4 software (Cambridge Electronic Design, Cambridge, England), and were delivered through speakers attached to the cage top. Speakers were connected to a RCA digital audio amplifier (Model STAV3870 Radioshack, Fort Worth, TX) that was interfaced with the computer. A series of 80 clicks $(10 \mathrm{~ms}$ duration) with a frequency of $1500 \mathrm{~Hz}$ were presented in fixed interstimulus intervals of $0.25,0.5,1,2,4$, and $8 \mathrm{~s}$ at $85 \mathrm{db}$ compared to a background of $70 \mathrm{~dB}$. The blocks of each ISI were presented in random order and the analog-to- digital sampling rate was $1600 \mathrm{~Hz}$. Waveforms were filtered between 1 and $500 \mathrm{~Hz}$, baseline corrected at zero and individual sweeps were rejected for movement artifact, based on a criteria two times the root-mean-squared amplitude per mouse. Average waves were created from $50 \mathrm{~ms}$ prestimulus to $200 \mathrm{~ms}$ poststimulus. Mice were allowed $15 \mathrm{~min}$ to acclimate to the Faraday cage prior to stimulus onset.

\section{Determination of ISI Curve for P20, N40, and P80 Components}

The ISI paradigm was evaluated in the eight mice used in the control treatment group as well as 18 additional C57BL/ $6 \mathrm{~J}$ mice $(n=26)$. The P20 was measured by picking the maximum positive deflection between 15 and $30 \mathrm{~ms}$. The N40 was determined by picking the most negative deflection between 25 and $60 \mathrm{~ms}$. The P80 was calculated by picking the most positive deflection between 60 and $110 \mathrm{~ms}$ (Siegel et al, 2003). The $\mathrm{P} 20, \mathrm{~N} 40$, and $\mathrm{P} 80$ were examined individually for a main effect of ISI using a repeatedmeasures ANOVA, with the amplitude of response at each ISI as a repeated measure for each mouse.

\section{Effects of Haloperidol and Olanzapine on the Mouse Auditory ERPs}

The amplitude of response to the P20, N40, and P80 waveform was calculated for each mouse in each treatment group $(n=55)$ on postoperative day 7 . The amplitude from the peak of the P20 to the trough of the N40 was then calculated to facilitate comparison with previous literature, as it is reported to be a more stable measure than either component alone (Cook et al, 1968; Stevens et al, 1996). A repeated-measures ANOVA was used to evaluate the effects of drug and ISI for each component analyzed. Drug condition was designated the independent variable and interstimulus interval was the repeated measure for each mouse. Significant main effects were followed by a planned comparison using Statistica 6 (Statsoft, Inc. Tulsa, OK) on a Pentium III personal computer.

\section{RESULTS}

Evaluation of ISI Relationship for P20, N40, and P80 in C57BL/6J Mice

Repeated-measures ANOVA indicated that there was a main effect of interstimulus interval on the N40 component within the 26 control mice $(\mathrm{F}(5,125)=3.8, p<0.01)$. However, neither the P20 $(\mathrm{F}(5,125)=0.27, p=0.93)$ nor the P80 $(\mathrm{F}(5,125)=0.45, p=0.82)$ showed a main effect of interstimulus interval between $250 \mathrm{~ms}$ and $8 \mathrm{~s}$ (Figure 1). These data suggest that the mouse N40 shared characteristics with the N100 in humans.

Effects of Olanzapine and Haloperidol on the P20, N40, P80, and P20/N40 ERP

A repeated-measures ANOVA revealed a main effect of drug condition $(\mathrm{F}(6,48)=3.3, p<0.01)$ and ISI $(\mathrm{F}(5,240)=10.7$, $p<0.01$ ) on the N40 component, with all of the seven 

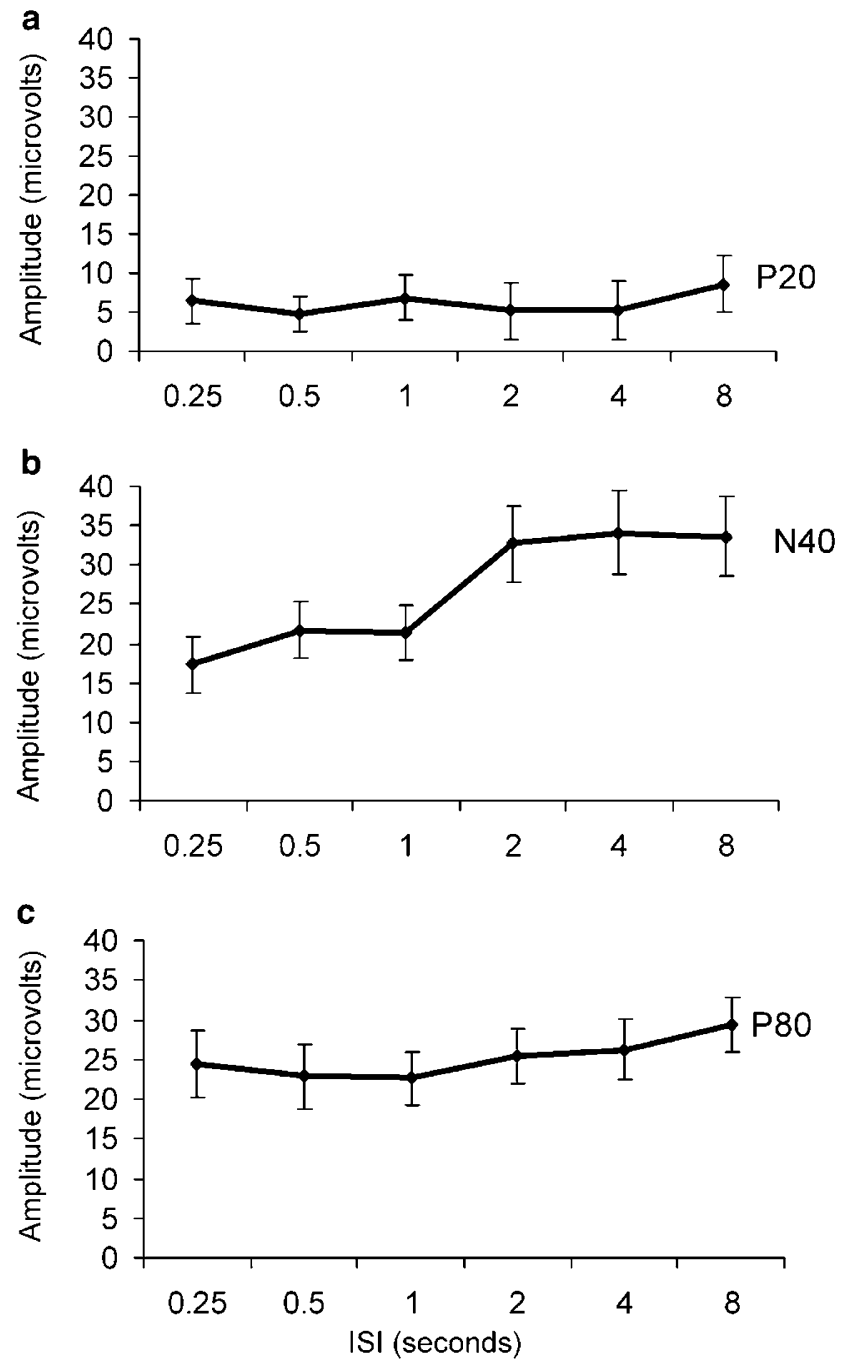

Figure I Amplitudes \pm SEM of the mouse P20, N40, and P80 components across all ISI in the control condition $(N=26)$ with a main effect of ISI on the N40 component, but not P20 or P80.

conditions in the analysis. A planned comparison analysis showed a significant difference between control and olanzapine $5 \mathrm{mg} / \mathrm{kg} /$ day across ISI on the N40 $(\mathrm{F}(1,48)=12.2, p<0.01)$. A significant difference was also found between olanzapine $5 \mathrm{mg} / \mathrm{kg} /$ day and haloperidol at each dose: $0.5 \mathrm{mg} / \mathrm{kg} /$ day $(\mathrm{F}(1,48)=4.2, p=0.04), 1 \mathrm{mg} / \mathrm{kg} /$ day $(\mathrm{F}(1,48)=5.9, p=0.02)$, and $2 \mathrm{mg} / \mathrm{kg} / \mathrm{day}(\mathrm{F}(1,48)=$ $8.9, p<0.01)$. The overall main effect of drug prompted an analysis of the vehicle group in comparison to olanzapine alone and haloperidol alone. A significant difference was found between control and the three olanzapine doses $(\mathrm{F}(3,27)=5.3, p=0.04)$, but not the three haloperidol doses $(\mathrm{F}(3,28)=1.0, p=0.4)$ on the $\mathrm{N} 40$ component.

A main effect of drug condition $(\mathrm{F}(6,48)=2.5, p=0.03)$ and ISI $(\mathrm{F}(5,240)=4.6, p<0.01)$ was also present in the P80 component along with a drug by ISI interaction $(\mathrm{F}(30,240)=1.5, p=0.05)$. While $5 \mathrm{mg} / \mathrm{kg} /$ day of olanzapine is not significantly different from any other condition on the P80, control differs from olanzapine $1 \mathrm{mg} / \mathrm{kg} /$ day $(\mathrm{F}(1,48)=4.5, \quad p=0.04)$ and olanzapine $2.5 \mathrm{mg} / \mathrm{kg} /$ day
$(\mathrm{F}(1,48)=6.8, p=0.01)$. Olanzapine $2.5 \mathrm{mg} / \mathrm{kg} /$ day is also statistically different from haloperidol at each dose, $0.5 \mathrm{mg} /$ $\mathrm{kg} /$ day $(\mathrm{F}(1,48)=7.7, p<0.01), 1 \mathrm{mg} / \mathrm{kg} /$ day $(\mathrm{F}(1,48)=5.9$, $p=0.02)$ and $2 \mathrm{mg} / \mathrm{kg} /$ day $(\mathrm{F}(1,48)=7.0, p=0.01)$. The lowest olanzapine dose differs from haloperidol at $0.5 \mathrm{mg} /$ $\mathrm{kg} /$ day $\quad(\mathrm{F}(1,48)=5.3, \quad p=0.02) \quad$ and $2 \mathrm{mg} / \mathrm{kg} /$ day $(\mathrm{F}(1,48)=4.7, p=0.03)$. Again, an analysis was performed to compare the control condition to the individual drugs. Unlike the N40, the P80 showed no significant difference between control and the three olanzapine doses $(\mathrm{F}(3,27)=2.1, p=0.13)$ or control and the three haloperidol doses $(\mathrm{F}(3,28)=0.06, p=0.98)$.

Since the component analysis portion of the study showed no main effect of ISI on the P80 and the drug condition portion displayed a main effect of ISI on the P80, this contradictory finding on the P80 prompted an evaluation of each drug-treatment group. As reported in the component analysis portion of this study, the P80 did not display an ISI response relationship in the control condition. A main effect of ISI on the P80 was found across the olanzapine drug condition $(\mathrm{F}(5,100)=4.1, p<0.01)$, but not the haloperidol condition $(\mathrm{F}(5,105)=1.2, p=0.32)$. These data suggest that olanzapine mediates an ISI response relationship on the P80 in C57BL/6J.

The P20/N40 component showed a main effect of drug condition $(\mathrm{F}(6,48)=3.5, p<0.01)$ and ISI $(\mathrm{F}(5,240)=19.9$, $p<0.01)$, with planned comparisons showing significant differences between control and olanzapine at $5 \mathrm{mg} / \mathrm{kg} /$ day $(\mathrm{F}(1,48)=16.3, p<0.01)$ and at $1 \mathrm{mg} / \mathrm{kg} /$ day $(\mathrm{F}(1,48)=5.3$, $p=0.03)$, but not at $2.5 \mathrm{mg} / \mathrm{kg} /$ day $(\mathrm{F}(1,48)=0.33, p=0.57)$. Like the N40 component, the P20/N40 displays a significant difference between olanzapine $5 \mathrm{mg} / \mathrm{kg} /$ day and each dose of haloperidol, $0.5 \mathrm{mg} / \mathrm{kg} /$ day $(\mathrm{F}(1,48)=5.7, \quad p=0.02)$, $1 \mathrm{mg} / \mathrm{kg} /$ day $(\mathrm{F}(1,48)=5.1, \quad p=0.03)$, and $2 \mathrm{mg} / \mathrm{kg} /$ day $(\mathrm{F}(1,48)=10.6, p<0.01)$. Analyses used to compared the control condition to the olanzapine group and the haloperidol group yielded a statistically significant difference between control and the three olanzapine doses $(\mathrm{F}(3,27)=5.3, p<0.01)$, but not the three haloperidol doses $(\mathrm{F}(3,28)=2.0, p=0.1)$.

No main effects were found on the P20 component. Figure 2 shows the mean with SEM for the effect of drug on the P20, N40, P80, and P20/N40 components. Figure 3 illustrates the grand average evoked potential for vehicle, haloperidol $(0.5 \mathrm{mg} / \mathrm{kg} /$ day and $2 \mathrm{mg} / \mathrm{kg} /$ day $)$ and olanzapine $(1 \mathrm{mg} / \mathrm{kg} /$ day and $5 \mathrm{mg} / \mathrm{kg} /$ day $)$ at each ISI.

\section{DISCUSSION}

Although the P50 component is often used to examine sensory gating in schizophrenia, the N100 is also a sensitive measure of sensory gating (Boutros et al, 1999). The interstimulus interval paradigm used to evaluate the mouse ERP components in this study has been described as a stable measure of sensory gating in schizophrenia (Erwin et al, 1994; Javitt et al, 2000). These studies indicate that schizophrenia patients show a decrease in amplitude of N100 response at long, but not short interstimulus intervals, compared to controls. The results of the current study suggest that the mouse N40 may be analogous to the human N100, based on the observation that it displays an ISI 


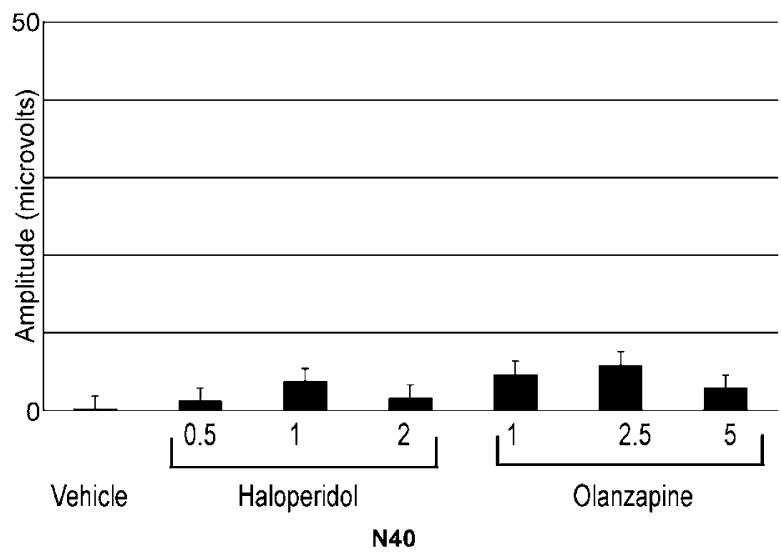

b

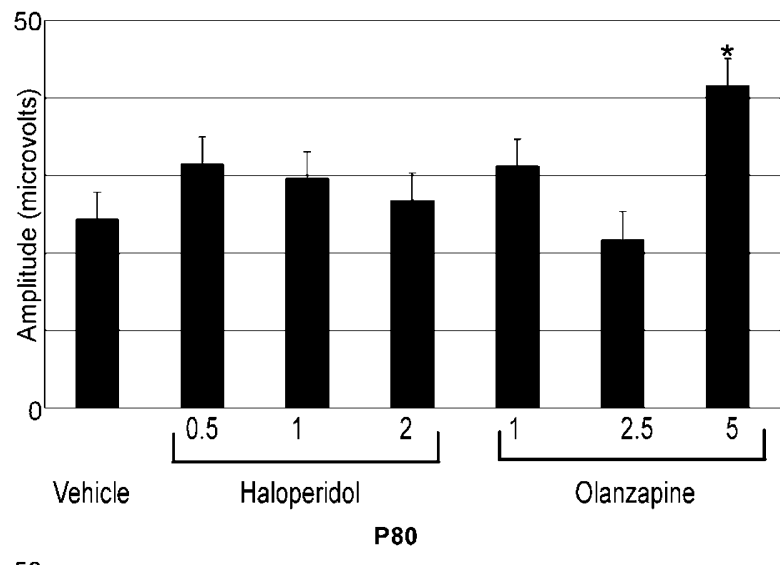

c

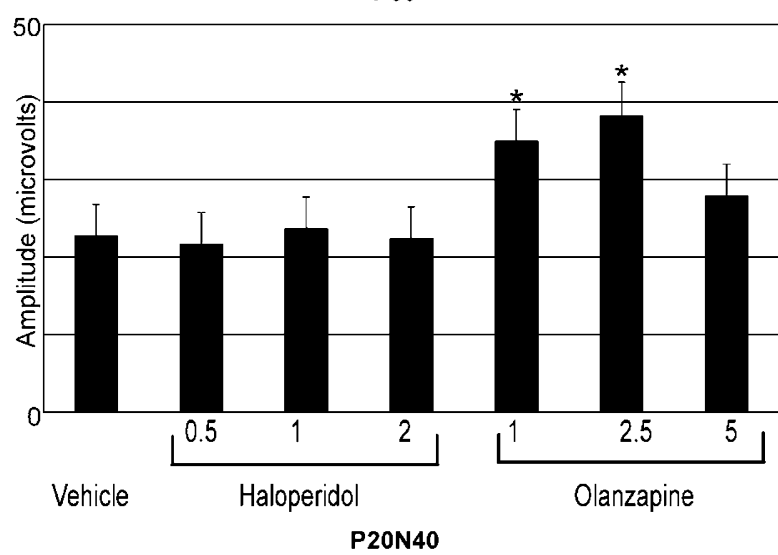

d

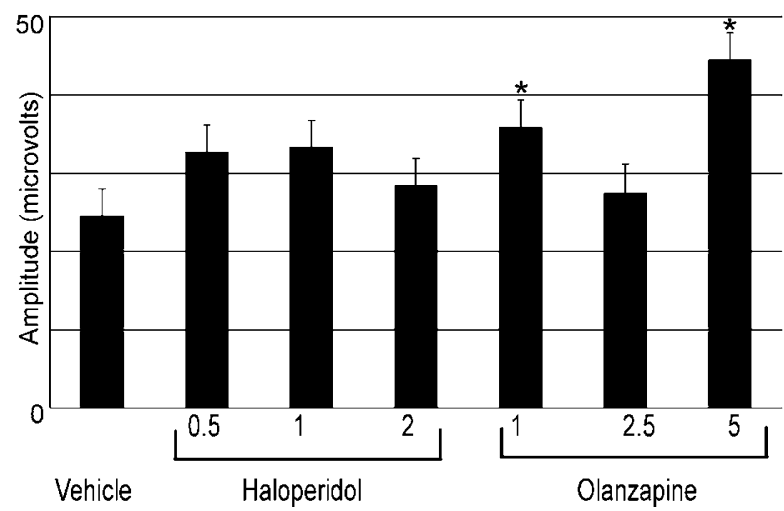

Figure 2 Amplitude $\pm S E M$ for the P2O, N40, P80, and P2O/N40 complex by drug condition. The asterisk denotes statistically significant difference between control and other drug conditions with $p<0.05$.

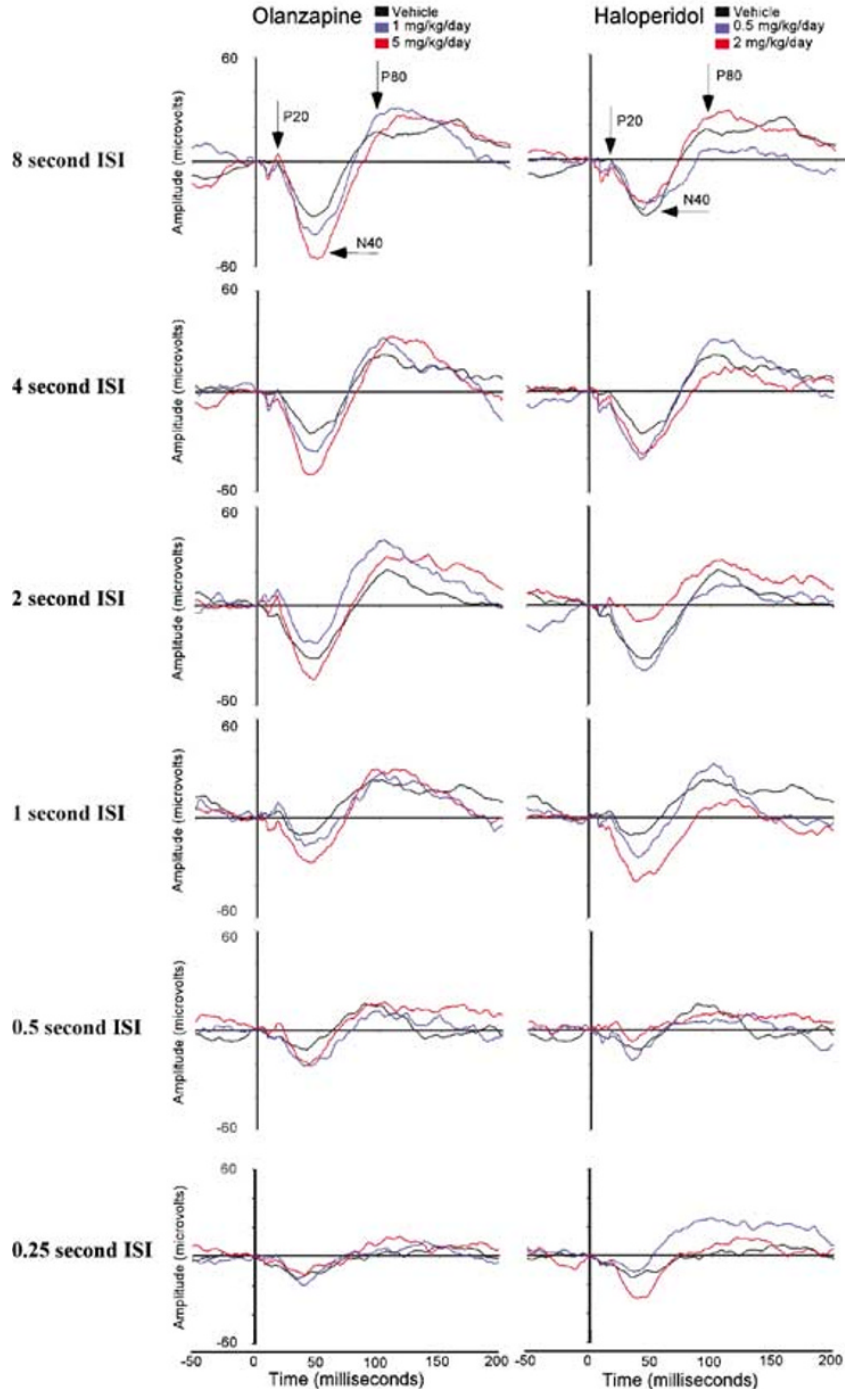

Figure 3 Grand average event-related potential at each ISI (rows) for control (black, columns I and 2), olanzapine I mg/kg/day (blue, column I), olanzapine $5 \mathrm{mg} / \mathrm{kg} /$ day (red, column I), haloperidol $0.5 \mathrm{mg} / \mathrm{kg} /$ day (blue, column 2), and haloperidol $2 \mathrm{mg} / \mathrm{kg} / \mathrm{day}$ (red, column 2). The middle doses of haloperidol and olanzapine are not displayed for clarity.

response relationship that has characteristics similar to that found with the human N100. The mouse P20, like the human P50, does not exhibit significant amplitude changes with varying stimulus intervals between 1 and $8 \mathrm{~s}$ (Onitsuka et al, 2000).

The antipsychotic treatment group analyses show that olanzapine increases the amplitude of the N40, P80, and P20/N40 components across ISI. This finding suggests that olanzapine may help transiently improve the N100 component abnormality found in schizophrenia. Our data also demonstrate a significant difference between haloperidol and olanzapine on two evoked components, suggesting that haloperidol and olanzapine may utilize a different mechanism to affect the auditory evoked potential at the doses administered. While the typical ratio of olanzapine to haloperidol doses is $5: 2$, the ratios of $10: 1,5: 1$, and $5: 2$ each display significant differences between the two drugs (Woods, 2003). Since D2 occupancies have been reported to 
be equivalent at $5 \mathrm{mg} / \mathrm{kg} /$ day of olanzapine and $1 \mathrm{mg} / \mathrm{kg} /$ day of haloperidol in rodents, it is likely that the source of this differential effect on the ERP is not related to D2 dopamine receptor blockade (Wadenberg et al, 2001). One possibility is that activity at the $5 \mathrm{HT} 2 \mathrm{~A}$ receptor could mediate this difference between haloperidol and olanzapine. However, affinity at the $5 \mathrm{HT} 2 \mathrm{~A}$ receptor is not the only distinction between these agents. Recent reports suggest that olanzapine increases serum corticosterone levels, which may also be related to its effects on weight gain in humans (Marx et al, 2003). In addition to corticosterone, olanzapine increases serum progesterone and allopregnanolone, raising the possibility that its effects on ERPs may be related to hormonal modulation of brain activity as well as any direct receptor interactions (Marx et al, 2003). Consistent with this hypothesis, previous studies suggest that corticosterone as well as social isolation rearing decreases inhibition of the $\mathrm{P} 20 / \mathrm{N} 40$ in a paired click paradigm in mice and rats (Stevens et al, 2001, 1997). Our laboratory is currently investigating the possibility that olanzapine increases serum corticosterone levels, as well as evaluating the effects of corticosterone on evoked potentials using the ISI paradigm. Furthermore, we will investigate the ability of various antipsychotic treatments to reverse or mimic these effects.

Earlier reports indicate that older antipsychotic agents, including haloperidol, do not increase the amplitude of the N100 in patients with schizophrenia (Ford et al, 1994; Roth et al, 1991). We are unaware of data evaluating the differential effects of olanzapine and haloperidol on the N100 evoked component in patients with schizophrenia. However, studies have suggested that N100 increases with clozapine administration may be related to a polymorphism in the 5HT-2A receptor gene (Tsai et al, 2000; Umbricht et al, 1998; Yu et al, 2001). Additionally, the effects of antipsychotic medications on the N100 have not been examined in the context of the ISI response relationship to the best of our knowledge. However, there are previous data to suggest that antipsychotic drugs with an affinity for the serotonin receptor such as olanzapine may normalize impaired gating of the human P50 auditory evoked potential. More selective antipsychotic drugs, like haloperidol, have no effect on P50 gating using the paired click task (Freedman et al, 1983; Light et al, 2000; Myles-Worsley, 2002). Other reports suggest that P50 amplitude increases with haloperidol treatment, while N100 amplitude decreases or remains unchanged (Ford et al, 1994; Roth et al, 1991). Therefore, the pharmacological effects of any antipsychotic agent on one component may not extend to other portions of the auditory evoked potential. The current study examines the effects of haloperidol and olanzapine in a mouse model of N100 auditory processing using trains of stimuli between 0.25 and $8 \mathrm{~s}$ ISI. The main finding of this study suggests that olanzapine may help improve impaired processing of the N100 in schizophrenia, while haloperidol does not.

There are several limitations to the current study. The lack of a pretreatment group prevents the evaluation of a within-subjects design. The focus of the current report was on the amplitude and processing of the N40 potential as a model for human N100 abnormalities. As such, we utilized the ISI stimulus paradigm that is optimal for comparison to N100 tasks in humans. Additionally, we have included analysis of the P20 component in an attempt to further characterize the effects of antipsychotic treatment across a broader array of endophenotypic markers related to schizophrenia. Previous studies of a paired click-gating task in $\mathrm{C} 57 \mathrm{Bl} / 6 \mathrm{~J}$ mice in our group found a mean amplitude of $26 \mu \mathrm{V}$ for the P20 evoked potential (Connolly et al, 2004). Power analyses indicate that there is an $89 \%$ probability of detecting a meaningful difference of $10 \mu \mathrm{V}(40 \%)$ of the expected mean, with a case correlation of 0.1 and a sample size of eight mice per group, as designed in the current report. However, since the mean amplitude of the P20 response was only $5 \mu \mathrm{V}$ in the current study, it is likely that there was not sufficient power to detect a meaningful change in amplitude, even if it had occurred. For example, there is only a $25 \%$ chance of detecting an $80 \%$ increase in amplitude from 5 to $9 \mu \mathrm{V}$ under these conditions. Therefore, the finding of no main effect of drug on the P20 is likely due to a lack of statistical power. The current data will serve as a source for the determination of the power for these future studies. Additionally, while there is no drug by ISI interaction on the N40, this could also be due a lack of statistical power, especially at short ISI where overall amplitudes are lower. Future studies could examine other inbred strains with larger P20 amplitudes, different stimulus conditions that augment P20 and N40 responses or larger sample sizes.

A third limitation to our interpretation of the data relates to the linkage between specific evoked components in mice and humans. The ISI response pattern used in this study is only one method to validate the analogy between the mouse N40 and human N100. Future studies will evaluate other methods to determine mouse and human analogous components. Moreover, we have presented data, which suggest that the N40 in mice is more similar to the N100 in humans. Yet others have proposed that this same component is similar to the human P50. If we are correct that the mouse N40 is analogous to the human N100, the current study suggests that olanzapine, but not haloperidol, may improve N100 deficits in schizophrenia. Future studies can examine this hypothesis in people with schizophrenia.

\section{ACKNOWLEDGEMENTS}

This work was supported by Eli Lilly and Co., P50 MH 6404501, and The Stanley Medical Research Institute. We would like to thank Dr Karen E Stevens for her guidance and helpful comments throughout this study. None of us have any involvement, financial or otherwise, that might potentially bias the work contained in this manuscript.

\section{REFERENCES}

Adler LE, Rose G, Freedman R (1986). Neurophysiological studies of sensory gating in rats: effects of amphetamine, phencyclidine, and haloperidol. Biol Psychiatry 21: 787-798.

Andersen MP, Pouzet B (2001). Effects of acute versus chronic treatment with typical or atypical antipsychotics on D-amphetamine-induced sensorimotor gating deficits in rats. Psychopharmacology (Berl) 156: 291-304.

Beasley Jr CM, Tollefson G, Tran P, Satterlee W, Sanger T, Hamilton S (1996). Olanzapine versus placebo and haloperidol: 
acute phase results of the North American double-blind olanzapine trial. Neuropsychopharmacology 14: 111-123.

Boutros NN, Belger A, Campbell D, D’Souza C, Krystal J (1999). Comparison of four components of sensory gating in schizophrenia and normal subjects: a preliminary report. Psychiatry Res 88: 119-130.

Boutros NN, Bonnet KA, Millana R, Liu J (1997). A parametric study of the N40 auditory evoked response in rats. Biol Psychiatry 42: 1051-1059.

Braff DL, Geyer MA (1990). Sensorimotor gating and schizophrenia. Human and animal model studies. Arch Gen Psychiatry 47: 181-188.

Budd TW, Barry RJ, Gordon E, Rennie C, Michie PT (1998). Decrement of the N1 auditory event-related potential with stimulus repetition: habituation vs refractoriness. Int J Psychophysiol 31: 51-68.

Cadenhead KS, Braff DL (2002). Endophenotyping schizotypy: a prelude to genetic studies within the schizophrenia spectrum. Schizophr Res 54: 47-57.

Connolly PM, Maxwell CR, Liang YL, Kahn JB, Kanes SJ, Abel T et al (2004). The effects of ketamine vary among inbred mouse strains and mimic schizophrenia for the P80, but not P20 or N40 auditory ERP components. Neurochem Res, in press.

Cook JD, Ellinwood Jr EH, Wilson WP (1968). Auditory habituation at primary cortex as a function of stimulus rate. Exp Neurol 21: 167-175.

de Bruin NM, Ellenbroek BA, Cools AR, Coenen AM, van Luijtelaar EL (1999). Differential effects of ketamine on gating of auditory evoked potentials and prepulse inhibition in rats. Psychopharmacology (Berl) 142: 9-17.

Ehlers CL, Somes C, Thomas J, Riley EP (1997). Effects of neonatal exposure to nicotine on electrophysiological parameters in adult rats. Pharmacol Biochem Behav 58: 713-720.

Erwin RJ, Shtasel D, Gur RE (1994). Effects of medication history on midlatency auditory evoked responses in schizophrenia. Schizophr Res 11: 251-258.

Ford JM, White PM, Csernansky JG, Faustman WO, Roth WT, Pfefferbaum A (1994). ERPs in schizophrenia: effects of antipsychotic medication. Biol Psychiatry 36: 153-170.

Freedman R, Adler LE, Waldo MC, Pachtman E, Franks RD (1983). Neurophysiological evidence for a defect in inhibitory pathways in schizophrenia: comparison of medicated and drug-free patients. Biol Psychiatry 18: 537-551.

Frey P (1983). Cholecystokinin octapeptide levels in rat brain are changed after subchronic neuroleptic treatment. Eur J Pharmacol 95: 87-92.

Gallinat J, Mulert C, Bajbouj M, Herrmann WM, Schunter J, Senkowski D et al (2002). Frontal and temporal dysfunction of auditory stimulus processing in schizophrenia. Neuroimage 17: 110-127.

Gysling K, Beinfeld MC (1984). Failure of chronic haloperidol treatment to alter levels of cholecystokinin in the rat brain striatum and olfactory tuberclenucleus accumbens area. Neuropeptides 4: 421-423.

Iwanami A, Shinba T, Sumi M, Ozawa N, Yamamoto K (1994). Event-related potentials during an auditory discrimination task in rats. Neurosci Res 21: 103-106.

Javitt DC, Jayachandra M, Lindsley RW, Specht CM, Schroeder CE (2000). Schizophrenia-like deficits in auditory P1 and N1 refractoriness induced by the psychomimetic agent phencyclidine (PCP). Clin Neurophysiol 111: 833-836.

Kaplan GB, Leite-Morris KA, Keith DJ (1999). Differential effects of treatment with typical and atypical antipsychotic drugs on adenylyl cyclase and G proteins. Neurosci Lett 273: 147-150.

LaBossiere E, Glickstein M (1976). Histological Processing for the Neural Science. Charles C Thomas: Springfield.

Light GA, Geyer MA, Clementz BA, Cadenhead KS, Braff DL (2000). Normal P50 suppression in schizophrenia patients treated with atypical antipsychotic medications. Am J Psychiatry 157: 767-771.

Marx CE, VanDoren MJ, Duncan GE, Lieberman JA, Leslie Morrow A (2003). Olanzapine and clozapine increase the GABAergic neuroactive steroid allopregnanolone in rodents. Neuropsychopharmacology 28: 1-13.

McFarland WH, Vivion MC, Wolf KE, Goldstein R (1975). Reexamination of effects of stimulus rate and number on the middle components of the averaged electroencephalic response. Audiology 14: 456-465.

McMillen BA (1985). Comparative chronic effects of buspirone or neuroleptics on rat brain dopaminergic neurotransmission. J Neural Transm 64: 1-12.

Miyazato H, Skinner RD, Cobb M, Andersen B, Garcia-Rill E (1999a. Midlatency auditory-evoked potentials in the rat: effects of interventions that modulate arousal. Brain Res Bull 48: 545-553.

Miyazato H, Skinner RD, Garcia-Rill E (1999b. Sensory gating of the P13 midlatency auditory evoked potential and the startle response in the rat. Brain Res 822: 60-71.

Myles-Worsley M (2002). P50 sensory gating in multiplex schizophrenia families from a Pacific island isolate. $\mathrm{Am} \mathrm{J}$ Psychiatry 159: 2007-2012.

Onitsuka T, Ninomiya H, Sato E, Yamamoto T, Tashiro N (2000). The effect of interstimulus intervals and between-block rests on the auditory evoked potential and magnetic field: is the auditory P50 in humans an overlapping potential? Clin Neurophysiol 111: 237-245.

Picton TW, Hillyard SA, Krausz HI, Galambos R (1974). Human auditory evoked potentials. I. Evaluation of components. Electroencephalogr Clin Neurophysiol 36: 179-190.

Pincze Z, Lakatos P, Rajkai C, Ulbert I, Karmos G (2001). Separation of mismatch negativity and the $\mathrm{N} 1$ wave in the auditory cortex of the cat: a topographic study. Clin Neurophysiol 112: 778-784.

Roth WT, Goodale J, Pfefferbaum A (1991). Auditory eventrelated potentials and electrodermal activity in medicated and unmedicated schizophrenics. Biol Psychiatry 29: $585-599$.

Shelley AM, Silipo G, Javitt DC (1999). Diminished responsiveness of ERPs in schizophrenic subjects to changes in auditory stimulation parameters: implications for theories of cortical dysfunction. Schizophr Res 37: 65-79.

Siegel SJ, Connolly P, Liang Y, Lenox RH, Gur RE, Bilker B et al (2003). The effects of strain, novelty and NMDA blockade on auditory evoked potentials in mice. Neuropsychopharmacology 28: $675-682$.

Simosky JK, Stevens KE, Adler LE, Freedman R (2003). Clozapine improves deficient inhibitory auditory processing in DBA/2 mice, via a nicotinic cholinergic mechanism. Psychopharmacology (Berl) 165: 386-396.

Stevens KE, Bullock AE, Collins AC (2001). Chronic corticosterone treatment alters sensory gating in $\mathrm{C} 3 \mathrm{H}$ mice. Pharmacol Biochem Behav 69: 359-366.

Stevens KE, Freedman R, Collins AC, Hall M, Leonard S, Marks MJ et al (1996). Genetic correlation of inhibitory gating of hippocampal auditory evoked response and $\alpha$-bungerotoxinbinding nicotinic cholinergic receptors in inbred mouse strains. Neuropsychopharmacology 15: 152-162.

Stevens KE, Johnson RG, Rose GM (1997). Rats reared in social isolation show schizophrenia-like changes in auditory gating. Pharmacol Biochem Behav 58: 1031-1036.

Tarazi FI, Zhang K, Baldessarini RJ (2002). Long-term effects of olanzapine, risperidone, and quetiapine on serotonin $1 \mathrm{~A}, 2 \mathrm{~A}$ and $2 \mathrm{C}$ receptors in rat forebrain regions. Psychopharmacology (Berl) 161: 263-270.

Tsai SJ, Hong CJ, Yu YW, Lin CH, Song HL, Lai HC et al (2000). Association study of a functional serotonin transporter gene 
polymorphism with schizophrenia, psychopathology and clozapine response. Schizophr Res 44: 177-181.

Umbricht D, Javitt D, Novak G, Bates J, Pollack S, Lieberman J et al (1998). Effects of clozapine on auditory event-related potentials in schizophrenia. Biol Psychiatry 44: 716-725.

Wadenberg ML, Soliman A, VanderSpek SC, Kapur S (2001). Dopamine $\mathrm{D}(2)$ receptor occupancy is a common mechanism underlying animal models of antipsychotics and their clinical effects. Neuropsychopharmacology 25: 633-641.
Woods SW (2003). Chlorpromazine equivalent doses for the newer atypical antipsychotics. J Clin Psychiatry 64: 663-667.

Yu YW, Tsai SJ, Yang KH, Lin CH, Chen MC, Hong CJ (2001). Evidence for an association between polymorphism in the serotonin-2A receptor variant (102T/C) and increment of N100 amplitude in schizophrenics treated with clozapine. Neuropsychobiology 43: 79-82. 